\title{
Weight Reduction Increases Adipose Tissue Lipoprotein Lipase Responsiveness in Obese Women
}

\author{
Robert H. Eckel and Trudy J. Yost \\ Division of Endocrinology, Department of Medicine, University of Colorado Health Sciences Center, Denver, Colorado 80262
}

\begin{abstract}
Lipoprotein lipase was measured in gluteal adipose tissue from nine obese $(90.6 \pm 2.7 \mathrm{~kg})$ women fasting and after the intravenous infusion of insulin and glucose before, immediately after, and 3 mo subsequent to a $14.0 \pm 1.8 \%(\bar{x} \pm$ SEM) weight reduction. Fasting adipose tissue lipoprotein lipase activity (ATLPL) decreased from 5.3 to $2.3 \mathrm{nEq}$ FFA/10 6 cells per min $(P<0.02)$ immediately after weight reduction, yet after weight maintenance, higher levels were again found $\left(6.1 \mathrm{nEq}\right.$ FFA $/ 10^{6}$ cells per min). Although responsiveness of ATLPL to 40 $\mathrm{mU} / \mathrm{m}^{2}$ per $\mathrm{min}$ of insulin infusion over $6 \mathrm{~h}$ was absent before weight loss, increases were seen immediately after weight loss $(\Delta 0.8, P=0.05)$ and more so $(\Delta 7.7, P<0.01)$ after 3 mo. Moreover, whereas before weight loss the ATLPL response to ingested mixed meals $(\Delta 0.9)$ was minimal, in the maintained reduced-obese state a marked increase was seen $(\Delta 12.6, P$ $=0.02$ ). Thus, because ATLPL is important to lipid filling in adipose tissue, the maintenance of high levels of fasting ATLPL and the increase in enzyme responsiveness in the reduced-obese state could play an important role in the resumption of the obese state, which so commonly follows weight reduction.
\end{abstract}

\section{Introduction}

Despite uncertainties about the pathophysiology of obesity in man, experience indicates that the reduced-obese state is a limited accomplishment, at best, for most (1-3). The assumption that reestablishment of the more obese state simply reflects the continued expression of pathophysiologic processes that originally led to obesity fails to consider the potential uniqueness of the reduced-obese state. For instance, in the study of Leibel and Hirsch (4), the caloric requirement per meter squared for weight maintenance in reduced-obese subjects was $28 \%$ less than that needed before weight reduction and $24 \%$ less than isocaloric intakes for lean controls.

An increased efficiency of energy storage in the reducedobese state could also facilitate reacquisition of lost weight. The maintenance of adipose tissue triglyceride stores is largely dependent on the delivery of lipoprotein-derived triglyceride fatty acids to adipocytes wherein reesterification occurs $(5,6)$. This pathway requires lipoprotein lipase that is synthesized

Address all correspondence to Dr. R. H. Eckel, Box B151, Division of Endocrinology, University of Colorado Health Sciences Center, Denver, CO 80262.

Received for publication 14 November 1986 and in revised form 27 April 1987.

J. Clin. Invest.

(C) The American Society for Clinical Investigation, Inc. 0021-9738/87/10/0992/06 \$2.00

Volume 80, October 1987, 992-997 within adipocytes and transported to the capillary endothelium where chylomicron and very low density lipoprotein triglyceride hydrolysis ensues (7).

In human obesity, increases in the amount of adipose tissue lipoprotein lipase activity (ATLPL) ${ }^{1}$ per fat cell, measured after an overnight fast, have been repeatedly found $(6,8-13)$. After weight loss with variable periods of weight maintenance (4-28 wk), however, some studies have shown an increase (14, $15)$ whereas others a decrease $(16,17)$ or no change $(9)$ in the overnight-fasted enzyme activity. Thus. determination of fasting ATLPL alone may not adequately assess the overall ability of adipose tissue to mediate enhanced fatty acid uptake and triglyceride storage. We therefore measured not only fasting ATLPL, but also responsiveness of the lipase to intravenous insulin (and glucose) and to the ingestion of mixed meals before and after weight reduction to determine if reductions in body weight (and adipocyte size) might induce a mechanism by which reaccumulation of triglyceride stores (and body weight) could readily occur.

\section{Methods}

Nine obese women composed the study group. Each was a minimum of 27\% above ideal body weight according to the Metropolitan Life Insurance Company Standards of 1983 (18). At the time of study, body weight was at a maximum and had been stable for at least $3 \mathrm{mo}$. The mean body mass index (weight per height squared) was $33.9 \pm 1.2$ $(\bar{x} \pm \mathrm{SEM}) \mathrm{kg} / \mathrm{m}^{2}$. The subjects ranged in age from 21 to $41 \mathrm{yr}$ (mean at $33.4 \mathrm{yr}$ ). Individuals were excluded if they ingested drugs with known effects on glucose or lipid metabolism such as oral contraceptives, other estrogenic compounds, diuretics, or other antihypertensive medications. All subjects were free of acute and chronic illnesses and, other than obesity, physical examinations were normal. After ingestion of 75 g of glucose, all had a normal 3-h glucose tolerance test (19). Also, triiodothyronine resin uptake, total thyroxine, thyrotropin, electrolytes, calcium, liver panel, phosphorous, magnesium, complete blood count, and urine dipstick were normal in all. Fasting serum cholesterol and triglycerides were also normal in all subjects.

Percentage body fat was determined by $(a)$ calculations from measurements of lean body mass by total body potassium (20) and (b) extrapolated from skinfold conversion tables after measurements of iliac and triceps skinfold thicknesses with calipers (21). Waist-to-hip ratios were determined according to Kissebah et al. (22). By their criteria, three out of nine subjects had abdominal adipose predominance (ratio > 0.85 ); zero out of nine, pelvic predominance (ratio $<0.76$ ); and six out of nine, indeterminate ratios (ratio $=0.76-0.85$ ).

All studies were approved by the Human Subjects Committee and performed at the General Clinical Research Center at the University of Colorado Health Sciences Center after informed consent was obtained. Before each study of ATLPL, all subjects consumed an isocaloric formula containing $45 \%$ carbohydrate, $40 \%$ fat, and $15 \%$ protein for $2 \mathrm{~d}$.

Euglycemic clamp studies were carried out after an overnight fast,

1. Abbreviation used in this paper: ATLPL, adipose tissue lipoprotein lipase. 
as previously described (23). On separate days, insulin infusion rates of $15 \mathrm{mU} / \mathrm{m}^{2}$ per min and $40 \mathrm{mU} / \mathrm{m}^{2}$ per min were chosen. Basal serum glucose concentrations were determined on the morning of the clamp and served as the standard, which establishes the variable glucose infusion needed to maintain euglycemia over the 6-h study. For the clamps carried out after weight reduction and 3 mo of isocaloric stabilization, glucose was infused at a rate that maintained the fasting serum glucose concentration at the level utilized for the initial clamps before weight loss. Steady state serum insulin concentrations were calculated as the mean of eight samplings obtained throughout the infusion period.

Fasting and serial ( 180 and $360 \mathrm{~min}$ into the clamp) gluteal adipose tissue biopsies were performed for measurements of ATLPL. Both the biopsy technique and measurements of the lipase activity have been previously described (23). Briefly, ATLPL was eluted from adipose tissue pieces (40-45 mg) into Krebs-Ringer phosphate buffer ( $\mathrm{pH} 7.4$ ) containing heparin ( $13.3 \mu \mathrm{g} / \mathrm{ml}$, from beef lung; Upjohn Co., Kalamazoo, MI). Enzyme activity was measured as hydrolyzed ${ }^{14} \mathrm{C}$-labeled fatty acids after incubation of $0.1 \mathrm{ml}$ eluted enzyme with $0.1 \mathrm{ml}$ substrate for $45 \mathrm{~min}$. The substrate was prepared with $5 \mathrm{mg}$ unlabeled triolein (Sigma Chemical Co., St. Louis, MO), $4 \mu \mathrm{Ci}\left[1-{ }^{14} \mathrm{C}\right]$ triolein (Amersham Corp., Arlington Heights, IL), and $0.24 \mathrm{mg}$ egg lecithin (Calbiochem-Behring Corp., La Jolla, CA), all emulsified with $2 \mathrm{M}$ Tris- $\mathrm{HCl}$ buffer containing $10 \%$ fatty acid-poor bovine serum and normal human serum ( $4.0 \mathrm{ml}$ final volume). Using frozen postheparin plasma, the coefficient of variation for determination of lipolytic activity was $4.2 \%$ ( $n=3$ independent determinations).

To determine fat cell size and number, $100 \mathrm{mg}$ of adipose tissue was digested according to the method of Rodbell (24) in Krebs-Ringer bicarbonate buffer containing collagenase $(3 \mathrm{mg} / \mathrm{ml})$ and albumin $(4 \mathrm{~g} / \mathrm{dl})$. After filtration through nylon mesh $(250 \mu \mathrm{m})$, centrifugation at $400 \mathrm{~g}$ for $2 \mathrm{~min}$, and washing twice in buffer, adipocyte size was determined with a calibrated microscope by the method of DiGirolamo et al. (25). Adipocyte number was calculated according to the method of Goldrick (26). Serum insulin levels were measured by a double antibody radioimmunoassay using the technique of Desbuquois and Aurbach (27).

Measurements of ATLPL were also made after an overnight fast (before) and subsequent to the administration of seven hourly meals. Each meal consisted of $250 \mathrm{kcal}$ of palatable food, which was easily ingested within $10 \mathrm{~min}$. Over the 6-h period, $50 \%$ of the total calories were carbohydrate; $16 \%$, protein; and $34 \%$, fat. On a separate day, an identical protocol was implemented; however, subjects were simply and briefly $(2.5 \mathrm{~min})$ exposed to the meals without ingestion.

Weight loss was accomplished over 1 mo (inpatient) to 3 mo (outpatient) by administering four times per day a 200 -kcal formula (7057; Mead Johnson \& Co., Evansville, IN) containing 48\% carbohydrate, $28 \%$ casein protein, and $30 \%$ fat. At the conclusion of the hypocaloric period, isocaloric formula was again ingested and $2 \mathrm{~d}$ later a euglycemic clamp ( $40 \mathrm{mU} / \mathrm{m}^{2}$ per min insulin) with adipose tissue biopsies was performed. Subjects were then placed on isocaloric food plans $(17.5-35.0 \mathrm{kcal} / \mathrm{kg}$ per day), which were calculated on the basis of amount of weight loss and activity level, to maintain the reduced-obese state for an additional $3 \mathrm{mo}$. To assure weight maintenance, caloric adjustments, when necessary, were made weekly in the outpatient clinic of the General Clinical Research Center. At the end of 3 mo, isocaloric formula feedings were again administered and the initial investigations, including the euglycemic clamps and mixed meal studies were repeated. The approximate entrance level of physical activity was controlled for each patient throughout the investigation.

Fasting glucose, insulin, and ATLPL data obtained before and after weight loss with 3 mo of isocaloric weight maintenance were calculated from the average of four fasting measurements, each on separate days (before each clamp [ $n=2]$ and food exposure study [ $n=2]$ ) for each subject. Fasting ATLPL measured immediately after weight loss was a single determination.

Student's $t$ test for paired distributions, the Wilcoxin matched-pairs signed-ranks test, and the Pearson product-moment correlation were used for statistical analyses.
Table I. Clinical Data Before and After Weight Reduction

\begin{tabular}{lcc}
\hline & Obese $(n=9)$ & $\begin{array}{l}\text { Reduced-obese } \\
(n=9)^{*}\end{array}$ \\
\hline Weight $(\mathrm{kg})$ & $90.6 \pm 2.7$ & $78.1 \pm 3.5^{\ddagger}$ \\
Weight per height squared $\left(\mathrm{kg} / \mathrm{m}^{2}\right)$ & $33.9 \pm 1.2$ & $29.5 \pm 1.3^{\ddagger}$ \\
Percent fat & & \\
$\quad$ Total body potassium & $44.6 \pm 2.2$ & $35.5 \pm 2.7^{\ddagger}$ \\
$\quad$ Skinfold thickness & $41.2 \pm 0.8$ & $36.7 \pm 1.2^{\ddagger}$ \\
Waist-to-hip ratio & $0.84 \pm 0.01$ & $0.79 \pm 0.01^{\ddagger}$ \\
Fasting glucose $(\mathrm{mg} / \mathrm{dl})^{\S}$ & $87.3 \pm 1.4$ & $83.3 \pm 1.4^{\prime \prime}$ \\
Fasting insulin $(\mu U / \mathrm{ml})^{8}$ & $22.5 \pm 5.7$ & $10.1 \pm 1.9^{\prime \prime}$ \\
Fat cell size $(p l)$ & $556 \pm 30$ & $469 \pm 32^{\prime \prime}$ \\
& & \\
\hline
\end{tabular}

$\bar{x} \pm$ SEM.

* Obtained after 3 mo of weight stabilization.

${ }^{\ddagger} P<0.001$.

$\S \bar{x}$ of four determinations per patient.

" $P<0.05$.

\section{Results}

Immediately after 1-3 mo of hypocaloric formula feeding, body weight was reduced from $90.6 \pm 2.7$ to $78.7 \pm 3.6 \mathrm{~kg}$, an overall deficit of $11.8 \pm 1.5 \mathrm{~kg}$. After an additional $3 \mathrm{mo}$ of isocaloric weight maintenance, these values were essentially unchanged, $78.1 \pm 3.5$ and $12.4 \pm 1.4 \mathrm{~kg}$, respectively (Table I). During the maintenance phase, the change in body mass was minimal, $-0.6 \pm 1.0 \mathrm{~kg}$ (range from -6.1 to $3.0 \mathrm{~kg}$ ) (Table II). In one subject, an impending divorce resulted in anorexia and progressive weight loss $(-6.1 \mathrm{~kg}$ total), most of which occurred during the 1 st mo of the 3-mo maintenance period. As expected, the percentage of body weight attributed to nonlean tissue fell in all subjects. Moreover, there was good agreement between calculations of fat mass from total body potassium determinations and that extrapolated from skinfold thickness tables. The fall in waist-to-hip ratios in all subjects indicated the preferential reduction of abdominal vs. pelvic circumference. Significant $(P<0.05)$ reductions in fat cell size, fasting serum glucose, and insulin were also seen.

Immediately after weight loss (and $2 \mathrm{~d}$ of isocaloric formula feeding), fasting ATLPL was reduced from 5.3 \pm 0.9 to $2.3 \pm 0.7 \mathrm{nEq} \mathrm{FFA} / 10^{6}$ cells per min (paired analysis carried out for $n=8$ ) (Fig. 1) (Table II). However, subsequent to 3 mo of isocaloric weight maintenance an increase to $6.1 \pm 0.8 \mathrm{nEq}$ FFA $/ 10^{6}$ cells per min in fasting ATLPL occurred. As shown in Fig. 2, the change in fasting ATLPL from the initial determination to that obtained after weight reduction and isocaloric weight maintenance was inversely related to the initial ATLPL activity. In other words, subjects with lower levels of fasting ATLPL before dieting had increases in the fasting enzyme in the reduced-obese state, whereas the opposite was true for women with higher fasting ATLPL before weight loss.

Before weight reduction, ATLPL failed to increase when insulin ( $40 \mathrm{mU} / \mathrm{m}^{2}$ per $\mathrm{min}$ ) and glucose were infused intravenously over $6 \mathrm{~h}$ (Fig. 3) (Table II). However, immediately after weight reduction an increase in the ATLPL response was seen $\left(\Delta 0.8 \pm 0.6 \mathrm{nEq}\right.$ FFA $/ 10^{6}$ cells per min, $\left.P=0.05\right)$. Yet, after maintenance of the reduced-obese state for an additional 3 mo, a further increase $\left(\Delta 7.7 \pm 2.4 \mathrm{nEq} F \mathrm{FF} / 10^{6}\right.$ cells per min) in the mean ATLPL response to insulin and glucose was seen. This was significantly greater than the lipase response to the 


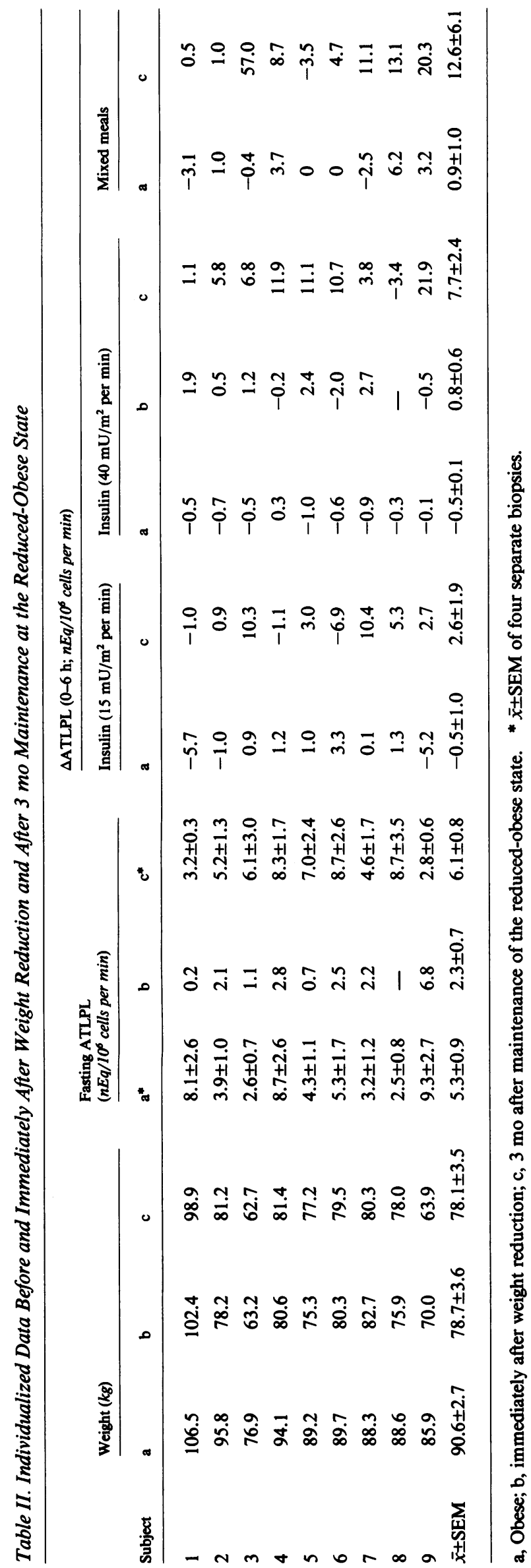

infusion both before $(P<0.01)$ and immediately after hypocaloric feeding $(P<0.02)$ (Fig. 3) (Table II). This change in the ATLPL response to intravenous insulin and glucose over the weight loss (and maintenance) interval correlated with the amount of weight reduction $(r=0.750, P<0.02)$. However, at no point did the ATLPL response to insulin $\left(40 \mathrm{mU} / \mathrm{m}^{2}\right.$ per min) and glucose correlate with the fasting value. Although a greater ATLPL response to insulin and glucose was also seen at $3 \mathrm{~h}$ into the infusion after weight reduction and isocaloric maintenance than before dieting, this difference failed to reach statistical significance (data not shown).

The responsiveness of ATLPL was also examined before and after weight reduction and isocaloric weight maintenance at an insulin infusion rate of $15 \mathrm{mU} / \mathrm{m}^{2}$ per min. Although a change in the ATLPL response from $-0.5 \pm 1.0$, before, to $2.6 \pm 1.9 \mathrm{nEq} \mathrm{FFA} / 10^{6}$ cells per min after weight reduction was noted, this did not reach statistical significance (Table II). However, despite lower steady state serum insulin concentrations at both insulin infusion rates ( 15 and $40 \mathrm{mU} / \mathrm{m}^{2}$ per min) after weight loss, both the sensitivity and overall responsiveness of ATLPL to insulin were increased (Fig. 4). Enhancement of insulin action as determined from euglycemic clamp studies after weight reduction and maintenance was also supported by increases in the amount of glucose required to sustain euglycemia: $222 \pm 21$ vs. $169 \pm 20 \mathrm{mU} / \mathrm{m}^{2}$ per $\min (P$ $<0.01)$ at $40 \mathrm{mU} / \mathrm{m}^{2}$ per min of insulin, and $118 \pm 13$ vs. $92 \pm 10 \mathrm{mU} / \mathrm{m}^{2}$ per $\mathrm{min}(P<0.05)$ at $15 \mathrm{mU} / \mathrm{m}^{2}$ per $\mathrm{min}$ of insulin infusion.

Although the euglycemic clamp has provided a useful tool to examine the regulation of ATLPL by insulin and glucose, the physiologic relevance of such studies remains unclear. The responsiveness of ATLPL to the ingestion of seven 250-cal $50 \%$ carbohydrate-containing meals administered on an hourly basis was therefore compared before and after 3 mo of maintenance at the reduced-obese weight. Before weight reduction, essentially no change in ATLPL occurred after mixed meal ingestion (Fig. 5) (Table II). As expected, a simple exposure to the meals without ingestion also failed to alter ATLPL (data not shown). However, after weight loss and isocaloric maintenance at the reduced weight, a substantial increase in the lipase response to food $\left(\Delta 12.6 \pm 6.1 \mathrm{nEq} F \mathrm{FF} / 10^{6}\right.$ cells per $\min , P=0.02$ ) was seen. The large variance related mostly to one subject in whom a $57-n E q$ FFA $/ 10^{6}$ cells per min increase in the ATLPL response occurred between the two periods. Similar to the $40-\mathrm{mU} / \mathrm{m}^{2}$ per min insulin clamp, there was no relationship between the response of ATLPL to food and fasting ATLPL measured before food ingestion. Again, a brief exposure to the meals without ingestion had no effect on ATLPL (data not shown).

\section{Discussion}

Previously, studies of ATLPL after reductions in body weight have been restricted to measurements of the fasting enzyme activity only $(9,14-17)$. As shown by others $(8,12,17,28-30)$, immediately after hypocaloric feeding and a mean weight reduction of 14\%, fasting ATLPL was lower. However, similar to the report of Sorbris et al. (9), where fasting ATLPL was unaltered in reduced-obese women after a 13-kg decrement and 2-3 wk of weight maintenance, our subjects experienced no change in fasting ATLPL. In other reports, weight reduction with variable periods of isocaloric weight maintenance has re- 


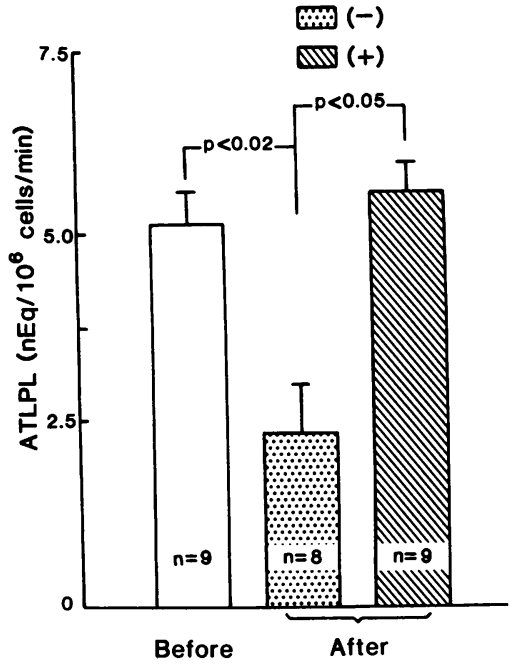

weight reduction with measurements before and after weight reduction plus stabilization was carried out in eight out of nine subjects.

sulted in increases $(14,15)$ or decreases $(16,17)$ in fasting ATLPL. As suggested by our own data (Fig. 2), one explanation for this discrepancy may be the variability in the initial activity of fasting ATLPL measured before weight reduction. This is particularly noteworthy when the studies of Schwartz and Brunzell $(14,15)$, where fasting ATLPL was lower, are compared with those of Reitman et al. (16) and Rebuffe-Serive et al. (17), where fasting ATLPL was higher. Taken together, these studies demonstrate that the change in fasting ATLPL after weight reduction (and maintenance) is inversely related to fasting ATLPL measured before dieting. Nevertheless, these reports suggest that the measurement of fasting enzyme activity alone may be insufficient to examine the putative role of

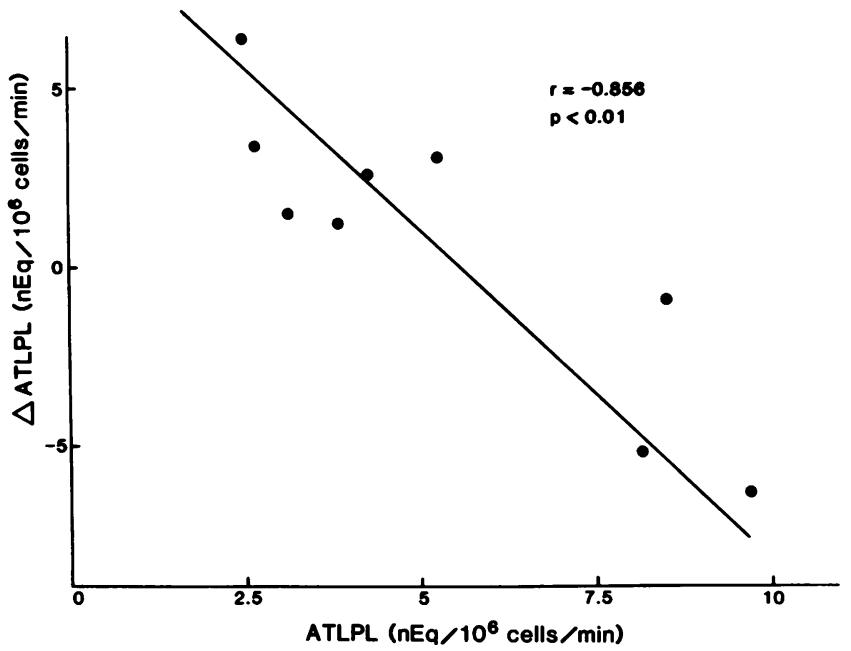

Figure 2. Change in fasting ATLPL after weight reduction vs. fasting ATLPL before dieting. The change $(\Delta)$ in fasting gluteal ATLPL in the interval between the initial determination and that obtained after weight reduction plus isocaloric weight maintenance is plotted on the ordinant; the initial determination of fasting ATLPL is on the abscissa. The portrayed $r$ value is a Pearson product-moment correlation coefficient.

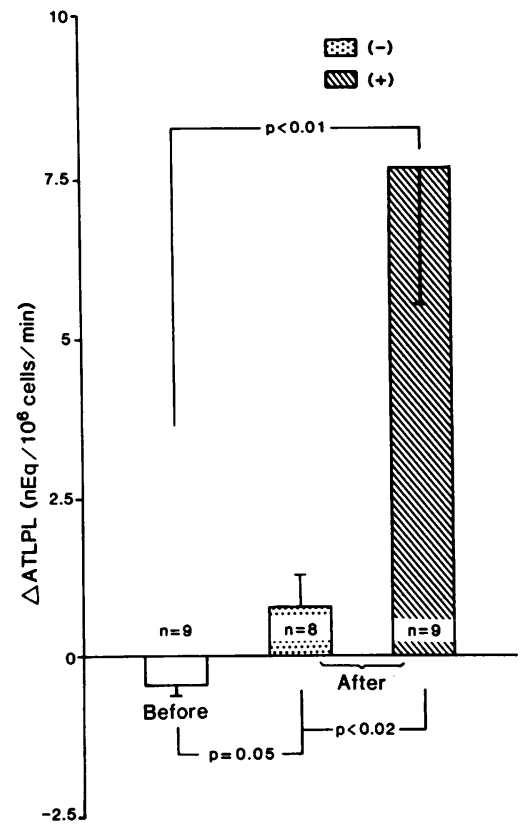

Figure 3. ATLPL responsiveness to insulin effect of weight reduction plus/minus stabilization. The change $(\Delta)$ in gluteal ATLPL after $6 \mathrm{~h}$ of insulin infusion ( $40 \mathrm{mU} / \mathrm{m}^{2}$ per $\mathrm{min}$ ) and maintenance of fasting euglycemia with a variable glucose infusion is shown before weight loss (open bar), immediately after weight loss (stippled bar), and after weight loss with 3 mo of isocaloric stabilization (hatched bar). Paired analysis of ATLPL immediately after weight loss with initial ATLPL and that obtained after weight loss plus 3 mo of isocaloric weight stabilization was carried out in eight out of nine subjects. Comparisons of ATLPL before and after weight loss plus stabilization was performed in all nine subjects.

ATLPL in the resumption of the obese state, which so commonly follows weight reduction.

In the obese state, ATLPL responsiveness to stimuli such as oral glucose $(31,32)$, intravenous glucose (33), and intravenous glucose and insulin $(13,34)$ may be blunted or delayed. In the current manuscript, no attempt has been made to compare ATLPL responsiveness to insulin in obese or reducedobese subjects with previously published data from nonobese controls. Normal weight subjects likely fail to gain weight be-

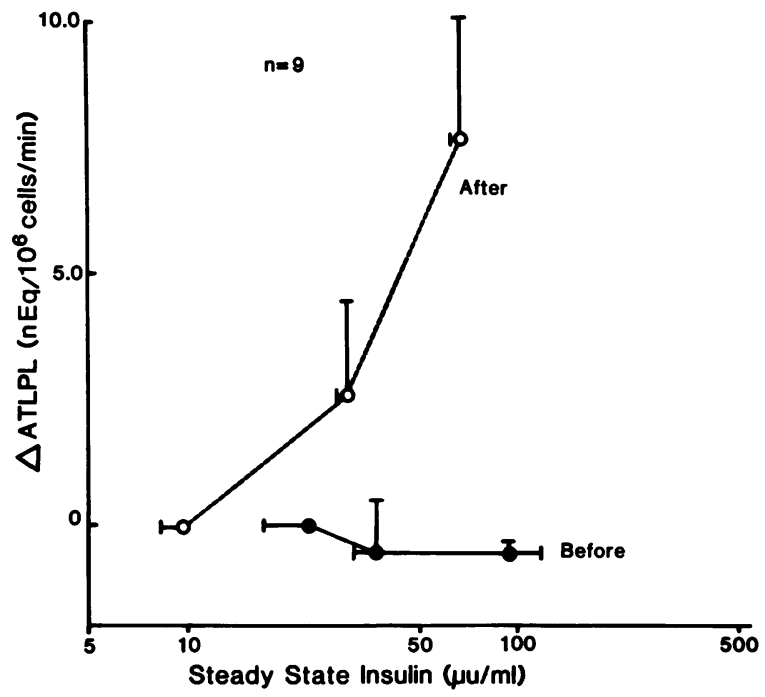

Figure 4. ATLPL responsiveness to insulin: effect of weight reduction. Fasting levels of insulin before (closed circle) and after weight loss plus 3 mo of stabilization (open circles) are shown before the insulin infusions at ATLPL of $0 \mathrm{nEq} / 10^{6}$ cells per min. ATLPL responses to 15 and $40 \mathrm{mU} / \mathrm{m}^{2}$ of insulin infusion are shown progressively to the right for each group. The ATLPL was determined over a 6-hr infusion of insulin plus glucose to sustain fasting euglycemia. 


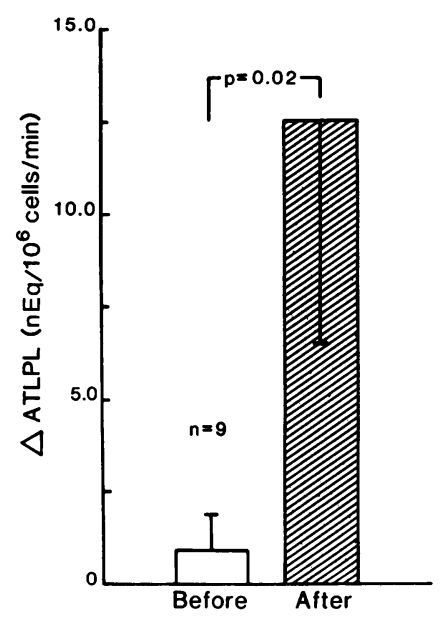

Figure 5. ATLPL response to mixed meal ingestion: Effect of weight reduction. The change $(\Delta)$ in ATLPL to 6 hourly ingested mixed meals is demonstrated for obese women before (open bar) and after weight reduction plus 3 months of isocaloric weight stabilization (hatched bar). Biopsies of gluteal adipose tissue for ATLPL were performed before and $10 \mathrm{~min}$ after the sixth hourly ingestion.

cause they have much lower fasting ATLPL $/ 10^{6}$ cells $(6,8-13)$. Moreover, as previously demonstrated (23), lean subjects with higher fasting ATLPL respond less to an insulin and glucose infusion than lean subjects with lower fasting lipase activities. Thus, in lean subjects, it would appear that triglyceride loading of adipocytes is maintained by a balance between fasting and stimulated lipase. Although $40 \mathrm{mU} / \mathrm{m}^{2}$ per min of intravenous insulin has increased gluteal ATLPL in some obese subjects (13), a subset of obese subjects previously studied and the women reported herein had a minimal, if any, ATLPL response to the infusion (or mixed meals). Thus, the maintenance of excessive fat cell size in obese women appears to be accomplished primarily by the elevated levels of fasting ATLPL. The failure of ATLPL to increase further in the setting of relative hyperinsulinemia is likely an appropriate response of adipose tissue to further limit triglyceride loading.

In the current study, immediately after hypocaloric feeding, ATLPL responsiveness to $40 \mathrm{mU} / \mathrm{m}^{2}$ per min of insulin significantly increased despite the decrease in fasting enzyme activity. After $3 \mathrm{mo}$ of isocaloric weight maintenance at the reduced weight, an additional increase in ATLPL was seen. Moreover, this increase occurred in the setting of a mean fasting enzyme activity that was slightly higher than that measured before hypocaloric formula feeding. This suggests that the lack of an insulin-mediated response before weight loss was not simply a consequence of increased fasting ATLPL, a relationship previously shown in lean subjects (23). The shift to the left of the ATLPL-insulin dose-response curve (despite lower levels of steady state serum insulin during the infusions), reduction in fasting serum glucose and insulin concentrations, and the increase in the amount of glucose required to sustain fasting euglycemia during both the 40 - and $15-\mathrm{mU} / \mathrm{m}^{2}$ per min clamps all point to an enhancement of insulin action in the reduced-obese state. Yet, unlike other parameters of insulin action such as glucose disposal and suppression of hepatic glucose output (35), the increased responsiveness of ATLPL occurs in the setting of elevated levels of fasting (basal) activity. This may relate to a unique and important role of ATLPL in the overall maintenance of nonlean body mass.

The change in ATLPL responsiveness to insulin after weight loss and isocaloric weight maintenance in the euglycemic clamp setting becomes increasingly relevant when the ATLPL response to the ingestion of mixed meals is considered. The limited increase in ATLPL to food before weight loss was similar to that reported in obese women by Iverius and Brunzell (36). Yet, in the reduced-obese state, the marked increase in ATLPL responsiveness in the present study was even greater than that reported in normal-weight men $8 \mathrm{~h}$ after the ingestion of four high carbohydrate meals (37). In the current study, the meal intake pattern was aimed to simulate a "routine" or outpatient setting wherein 1750 calories, or $\sim 55 \%$ of the estimated daily caloric consumption $(35 \mathrm{kcal} / \mathrm{kg})$, were administered over a 6-h period. Although composition of the routine diet may differ between subjects, the meals chosen were felt to be representative of the average diet in these subjects.

In summary, the increase in responsiveness of ATLPL to insulin and glucose, and mixed meals after a $14 \%$ weight reduction and $3 \mathrm{mo}$ of isocaloric stabilization points to a potential role of the lipase in the resumption of the obese state, which so commonly follows weight reduction. The ability of fasting ATLPL to predict relative weight gain in former cigarette smokers (38) and relative weight loss in dieting smokers (39) has been previously reported. Such an alteration in ATLPL responsiveness in the reduced-obese state does not indicate that increases in caloric intake must not also exist for reaccumulation of the lost weight, but does provide an environment wherein lipid filling of adipocytes can readily occur once higher levels of caloric intake resume. The mechanism by which this relative caloric deficit is perceived by appetite and weight regulatory centers of the hypothalamus remains an intriguing problem. Insights here would provide a much-needed hope to the millions of repeatedly frustrated dieters.

\section{Acknowledgments}

We thank Judy Prasad, Paul Awald, and members of the General Clinical Research Center (GCRC) Core Laboratory for their technical assistance, and Melissa Adams for her secretarial skills.

Support for this work was provided by National Institutes of Health grant AM-26356; a grant from the Mead Johnson \& Co., Nutritional Div.; and grant RR-00051 from the GCRC. Computation assistance was provided by CLINFO computer system funded under the GCRC grant.

\section{References}

1. Stunkard, A.-J., and M. McLaren-Hume. 1959. The results of treatment of obesity: a review of literature and report of a series. Arch. Intern. Med. 103:79-85.

2. Drenick, E. J., and D. Johnson. 1978. Weight reduction by fasting and semistarvation in morbid obesity: longterm follow-up. Int. J. Obesity. 2:123-132.

3. Wing, R. R., and R. W. Jeffrey. 1979. Outpatient treatment of obesity: a comparison of methodology and clinical results. Int. J. Obesity. 3:261-279.

4. Leibel, R. L., and J. Hirsch. 1984. Diminished energy requirements in reduced-obese patients. Metabolism. 33:164-170.

5. Hollenberg, C. H. 1966. The origin and glyceride distribution of fatty acids in rat adipose tissue. J. Clin. Invest. 45:205-216.

6. Taskinen, M., and E. A. Nikkila. 1977. Lipoprotein lipase activity in adipose tissue and in postheparin plasma in human obesity. Acta Med. Scand. 202:399-408.

7. Scow, R. O., E. J. Blanchette-Mackie, and L. G. Smith. 1980. Transport of lipid across capillary endothelium. Fed. Proc. 39:26102617.

8. Guy-Grand, B., and B. Bigorie. 1975. Effect of fat cell size, restrictive diet and diabetes on lipoprotein lipase release by human adipose tissue. Horm. Metab. Res. 7:471-475. 
9. Sorbris, R., B.-G. Petersson, and P. Nilsson-Ehle. 1981. Effects of weight reduction on plasma lipoproteins and adipose tissue metabolism in obese subjects. Eur. J. Clin. Invest. 11:491-498.

10. Arner, P., J. Bolinder, P. Engfeldt, and H. Lithell. 1982. The relationship between the basal lipolytic and lipoprotein lipase activities in human adipose tissue. Int. J. Obesity. 7:167-172.

11. Schwartz, R. S., J. D. Brunzell, and E. L. Bierman. 1979. Elevated adipose tissue lipoprotein lipase in the pathogenesis of obesity in the Prader-Willi syndrome. Trans. Assn. Am. Phys. 92:89-95.

12. Bosello, O., M. Cigolini, A. Battaggia, F. Ferrari, R. Micciolo, R. Olivetti, and M. Corsato. 1984. Adipose tissue lipoprotein lipase activity in obesity. Int. J. Obesity. 8:213-220.

13. Sadur, C. N., T. J. Yost, and R. H. Eckel. 1984. Insulin responsiveness of adipose tissue lipoprotein lipase is delayed but preserved in obesity. J. Clin. Endocrinol. \& Metab. 59:1176-1182.

14. Schwartz, R. S., and J. D. Brunzell. 1978. Increased adipose tissue lipoprotein lipase activity in moderately obese men after weight reduction. Lancet. 1:1230-1231.

15. Schwartz, R. S., and J. D. Brunzell. 1981. Increase of adipose tissue lipoprotein lipase activity after weight loss. J. Clin. Invest. 67:1425-1430.

16. Reitman, J. S., F. C. Kosmakos, B. V. Howard, M.-R. Taskinen, T. Kuusi, E.-A. Nikkila. 1982. Characterization of lipase activities in obese Pima Indians. Decreases with weight reduction. J. Clin. Invest. 70:791-797.

17. Rebuffe-Scrive, M., A. Basdevant, and B. Guy-Grand. 1983. Nutritional induction of adipose tissue lipoprotein lipase in obese subjects. Am. J. Clin. Nutr. 37:974-980.

18. Metropolitan height and weight tables. 1983. Stat. Bull. Metrop. Life Insur. Co. 64:2.

19. National Diabetes Data Group. 1979. Classification and diagnosis of diabetes mellitus and other categories of glucose intolerance. Diabetes. 28:1039-1057.

20. Forbes, G. H., F. Schultz, C. Cafarelli, and G. H. Amirhakimi. 1968. Effects of body size on potassium-40 measurement in the whole body counter (Tilt-chair techniques). Health Phys. 15:435-442.

21. Sloan, A., J. J. Burt, and C. S. Blyth. 1962. Estimation of body fat in young women. J. Appl. Physiol. 17:967-970.

22. Kissebah, A. H., N. Vydelingum, R. Murray, D. J. Evans, A. J. Hartz, R. K. Kalkhoff, and P. W. Adams. 1982. Relation of body fat distribution to metabolic complications of obesity. J. Clin. Endocrinol. \& Metab. 54:254-260.

23. Sadur, C. N., and R. H. Eckel. 1982. Insulin stimulation of adipose tissue lipoprotein lipase. Use of the euglycemic clamp techniques. J. Clin. Invest. 69:1119-1125.

24. Rodbell, M. 1964. Metabolism of isolated fat cells. I. Effects of hormones on glucose metabolism and lipolysis. J. Biol. Chem. 239:375-380.

25. DiGirolamo, M., S. Medlinger, and J. W. Fertig. 1971. A simple method to determine fat cell size and number in four mammalian species. Am. J. Physiol. 221:850-858.

26. Goldrick, R. B. 1967. Morphological changes in the adipocyte during fat deposition and mobilization. Am. J. Physiol. 212:777-782.

27. Desbuquois, B., and G. D. Aurbach. 1971. Use of polyethylene glycol to separate free and antibody-bound peptide hormones in radioimmunoassays. J. Clin. Endocrinol. \& Metab. 33:732-738.

28. Persson, B., B. Hood, and G. Angervall. 1970. Effects of prolonged fast on lipoprotein lipase activity eluted from human adipose tissue. Acta Med. Scand. 188:225-229.

29. Taskinen, M.-R., and E. A. Nikkila. 1978. Effects of caloric restriction on lipid metabolism in man. Atherosclerosis. 32:289-299.

30. Vessby, B., I. Selinus, and H. Lithell. 1985. Serum lipoprotein and lipoprotein lipase in overweight, type II diabetics during and after supplemented fasting. Arteriosclerosis. 5:93-100.

31. Dahms, W. T., P. Nilsson-Ehle, A. S. Garfinkel, R. L. Atkinson, G. A. Bray, M. Schotz. 1981. Lipoprotein lipase activity in adipose tissue from obese human beings. Int. J. Obesity. 5:81-84.

32. Brunzell, J. D., R. S. Schwartz, R. H. Eckel, and A. P. Goldberg. 1981. Insulin and adipose tissue lipoprotein lipase activity in humans. Int. J. Obesity. 5:685-694.

33. Taskinen, M.-R., and E. A. Nikkila. 1981. Lipoprotein lipase of adipose tissue and skeletal muscle in human obesity: response to glucose and to semistarvation. Metabolism. 30:810-817.

34. Eckel, R. H., C. N. Sadur, and T. J. Yost. 1986. Low-dose insulin increases adipose tissue lipoprotein lipase in normal weight but not obese women. Clin. Res. 34:58. (Abstr.)

35. Kolterman, O. G., J. Insel, M. Saekow, and J. M. Olefsky. 1980. Mechanism of insulin resistance in human obesity. Evidence for receptor and postreceptor defects. J. Clin. Invest. 65:1272-1284.

36. Iverius, P.-H., and J. D. Brunzell. 1985. Human adipose tissue lipoprotein lipase: changes with feeding in relation to postheparin plasma enzyme. Am. J. Physiol. 249:E107-E1 14.

37. Pagano Mirani-Oostdijk, C., L. Havekes, J. Terpstra, M. Frollich, C. M. Van Gent, and H. Jansen. 1982. Diurnal changes in serum triglycerides as related to changes in lipolytic enzymes, apo lipoproteins and hormones in normal subjects on a carbohydrate-rich diet. Eur. J. Clin. Invest. 13:301-309.

38. Carney, R. M., and A. P. Goldberg. 1986. Weight gain after cessation of cigarette smoking. A possible role for adipose-tissue lipoprotein lipase. N. Engl. J. Med. 310:614-616.

39. Eckel, R. H., C. N. Sadur, and T. J. Yost. 1984. Smoking, weight change, and lipoprotein lipase (Correspondence). N. Engl. J. Med. 311:259-260. 